\title{
Inhibited Lipid Peroxidation in Griseofulvin-Induced Experimental Protoporphyria
}

\author{
Dimtcho Adjarov, ${ }^{*}$ Kristina Pentieva, Aneta Ivanova, \\ Lyudmila IVANOVA, and Milka KeRIMOVA \\ Centre of Hygiene, Ecology, and Nutrition, Sofia 1431, Bulgaria
}

(Received August 2, 1993)

\begin{abstract}
Summary The pathogenesis of the liver damage in human erythropoietic protoporphyria is poorly understood. It has been suggested that an increased lipid peroxidation could be responsible for the hepatocellular injury in this condition. A model of mouse griseofulvin-induced protoporphyria was used for measurement of lipid peroxide formation and total iron content ir the liver. Male Balb $\mathrm{C}$ mice had free access to standard powder diet containing $1 \%$ griseofulvin for 1 week. Excessive amounts of hepatic protoporphyrin were established. The lipid peroxide level (expressed in terms of malondialdehyde) in total liver homogenate was decreased more than twice compared with that of control animals. The total content of liver iron was also significantly reduced. These results suggest that most probably lipid peroxidation does not play an essential role in the liver damage in hepatic protoporphyria.
\end{abstract}

Key Words: porphyrias, griseofulvin-induced protoporphyria, protoporphyrin, lipid peroxidation, iron

Erythropoietic protoporphyria (EPP) is an inherited disorder, which is related to a deficient activity of ferrochelatase (FC) (EC 4.99.1.1). The highly increased concentration of protoporphyrin (PP) in the bone marrow, plasma, and erythrocytes is the main biochemical consequence. PP diffuses from the red blood cells into the skin and promotes cutaneous photosensitivity [1]. Liver damage, which is common in EPP [2], may vary in severity from a slightly expressed lesion to fulminant failure with intrahepatic cholestasis. The hepatic involvement has also been associated with deposition of PP [3], but its pathogenesis remains obscure. It has been suggested that an increased lipid peroxidation (LPO) could be responsible for the hepatocellular injury $[1,4]$, but it has to be studied in detail,

*To whom correspondence should be addressed. 
as an antioxidative effect of PP has also been observed [5]. Data on hepatic content of iron, which relates to LPO [6], are also needed.

Griseofulvin (GF), an antibiotic used for treatment of fungal infections, is known to induce hepatic protoporphyria in mice $[7,8]$ by inhibiting FC [9]. Although murine GF-induced porphyria is mainly a hepatic and not an erythropoietic disorder, it has served as a model for studies of several aspects of human EPP [10]. We used this model for measurement of the formation of lipid peroxides and the concentration of iron in the liver in order to elucidate their role in the pathogenesis of hepatocellular injury caused by PP.

\section{MATERIALS AND METHODS}

Seven male Balb C mice (18-22 g) and 6 male Wistar albino rats were fed standard powder diet containing $1 \%$ GF for 1 week. Both species had respective controls fed standard diet without GF. All animals had free access to food and water. After the 1-week treatment, the animals were killed under light ether anaesthesia and their livers were removed and perfused via the portal vein with chilled saline. A total liver homogenate was prepared in $1.15 \mathrm{M} \mathrm{KCl}$ containing 0.1 $\mathrm{M}$ Tris, $\mathrm{pH} 7.4$, and was used for determination of total porphyrins and lipid peroxides. Total liver porphyrins were measured spectrofluorometrically according to Abbritti and De Matteis [11]. The dilution of the homogenates was $1: 300(\mathrm{w} /$ v) for GF-treated mice and 1:20 for all other animals. A Perkin-Elmer MPF-43 spectrofluorometer was used. Since PP is the major hepatic porphyrin deposited in this condition, total porphyrin levels were expressed as PP, but a coproporphyrin I standard was preferred, because of its greater stability. Finally, a recalculation for conversion to PP content was performed according to Poh-Fitzpatrick et al. [10].

A 1:50 dilution of homogenate was used for determination of lipid peroxides according to Yagi [12]. The results were presented in terms of malondialdehyde (MDA) and expressed per mg of protein, which was determined by the method of Schacterle and Pollack [13].

A piece of mouse liver, weighing $0.5 \mathrm{~g}$, was mineralized with a mixture of nitric acid-perchloric acid $(1: 4, \mathrm{v} / \mathrm{v})$, and the liberated iron was determined by flame atomic absorption spectroscopy using a Perkin-Elmer 3030 apparatus.

The results were statistically assessed by variation analysis at a significance level of $p<0.05$.

\section{RESULTS}

Extremely increased levels of hepatic PP were established in the GF-treated mice (Table 1). A very slight, although significant, elevation of porphyrins was found in the treated rats. After GF-treatment the concentration of lipid peroxides was decreased more than twice in the mice, but remained unchanged in the rats. Total liver iron in GF-treated mice $(318 \pm 73 \mathrm{nmol} / \mathrm{g}$, mean $\pm \mathrm{SD})$ was significantly 
Table 1. Hepatic values of PP and lipid peroxides.

\begin{tabular}{lccccc}
\hline \multirow{2}{*}{ Parameter } & \multicolumn{2}{c}{ Mice } & & \multicolumn{2}{c}{ Rats } \\
\cline { 2 - 3 } \cline { 5 - 6 } & Controls & GF-treated & & Controls & GF-treated \\
\hline Hepatic PP (nmol/g) & $1.16 \pm 0.35$ & $523 \pm 161^{* * *}$ & & $0.105 \pm 0.015$ & $0.140 \pm 0.029^{*}$ \\
$\begin{array}{l}\text { Lipid peroxides } \\
\text { (nmol MDA/mg protein) }\end{array}$ & $0.506 \pm 0.105$ & $0.241 \pm 0.064^{* * *}$ & & $0.312 \pm 0.048$ & $0.372 \pm 0.073$ \\
\hline
\end{tabular}

The results are expressed as mean \pm SD. Each group contained 6-8 animals. Comparisons with the controls: ${ }^{*} p<0.05 ;{ }^{* * *} p<0.001$.

reduced $(p<0.05)$ compared with the control value $(626 \pm 256 \mathrm{nmol} / \mathrm{g})$.

\section{DISCUSSION}

The excessive accumulation of PP in the liver of mice was evidence of successful development of hepatic protoporphyria in this species. It is known that in rats GF provokes less marked inhibition of FC [14]. The deposition of PP in the livers of treated rats was practically negligible. This could be considered an indirect evidence that the decreased LPO in mice is hardly due to GF, but should be attributed to the great amount of deposited PP.

It is difficult to point out the virtual reason for the diminished quantity of iron in the liver of GF-treated mice, but it is well known that iron as a transition metal accelerates free radical processes and, consequently, stimulates LPO [6]. One could thus suggest that the established low iron level in the liver of GF-treated mice could be one of the reasons for the inhibited formation of lipid peroxides in protoporphyria.

Koningsberger et al. [4], incubating HL 60 and HEP G 2 cells with exogenous PP, found a dose-dependent increase in intracellular $\mathrm{H}_{2} \mathrm{O}_{2}$ and suggested a possible involvement of activated LPO in cell injury. However, other in vitro studies argued against this assumption. Williams et al. [15] established an inhibitory dark effect of PP on the cytochrome P450 system, which could decrease the normal formation of free radicals accelerating the lipid peroxide formation. Imai et al. [5] found that PP IX inhibited the hepatic LPO stimulated by $\mathrm{Fe}^{2+}$ and/or ascorbic acid or NADPH system. All these findings are in accordance with our results demonstrating diminished formation of lipid peroxides in vivo. Besides the inhibited cytochrome P450 system and reduced liver iron content, a possible reason for the decreased LPO in hepatic protoporphyria could be the lack of formation of porphyrin-anion free radicals [15], which are formed under the influence of other porphyrins like uroporphyrin I, haematoporphyrin, and haematoporphyrin derivatives $[16,17]$. Such radicals activate LPO processes.

In conclusion, we suggest that most probably LPO does not play an essential role in the hepatocellular injury seen in protoporphyria. 


\section{REFERENCES}

1. Nordmann, Y. (1992): Erythropoietic protoporphyria and hepatic complications. $J$. Hepatol., 16, 4-6.

2. Rademakers, L.H.P.M., Cleton, M.I., Kooijman, C., Baart de la Faille, H., and Van Hattum, J. (1990): Early involvement of hepatic parenchymal cells in erythrohepatic protoporphyria? An ultrastructural study of patients with and without overt liver disease and the effect of chenodeoxycholic acid treatment. Hepatology, 11, 449-457.

3. Bloomer, J.R. (1988): The liver in protpoporphyria. Hapatology, 8, 402-407.

4. Koningsberger, J.C., Rademakers, L.H.P.M., Van Hattum, J., Baart de la Faille, H., Wiegman, L.J.I.M., Italiaander, E., Van Berge Henegouwen, G.P., and Marx, J.J.M. (1993): Inhibition of cell proliferation, increase of peroxide tone and ultrastructural alterations in Hep G 2 cells by exogenous protoporphyrin (abstract). Neth. J. Med., 42, A 24.

5. Imai, K., Aimoto, T., Sato, M., and Kimura, R. (1990): Antioxidative effect of several porphyrins on lipid peroxidation in rat liver homogenates. Chem. Pharm. Bull., 38, 258 260.

6. Saltman, P. (1989): Oxidative stress: A radical view. Semin. Hematol, 26, 249-256.

7. De Matteis, F., and Rimington, C. (1963): Disturbance of porphyrin metabolism caused by griseofulvin in mice. Br. J. Dermatol., 75, 91-104.

8. Hurst, E.W., and Paget, G.E. (1963): Protoporphyrin, cirrhosis and hepatomata in the livers of mice given griseofulvin. Br. J. Dermatol., 75, 105-112.

9. De Matteis, F., Gibbs, A.H., and Tephly, T.R. (1980): Inhibition of protohaem ferrolyase in experimental porphyria. Biochem. J., 188, 145-152.

10. Poh-Fitzpatrick, M.B., Sklar, J.F., Goldsman, C., and Lefkowitch, J.H. (1983): Protoporphyrin hepatopathy. Effect of chronic acid ingestion in murine griseofulvin-induced protoporphyria. J. Clin. Invest., 72, 1449-1458.

11. Abbritti, G., and De Matteis, F. (1971/1972): Decreased levels of cytochrome P-450 and catalase in hepatic porphyria caused by substituted acetamides and barbiturates. Importance of the allyl group in the molecule of the active drugs. Chem. Biol. Interact., 4, 281-286.

12. Suematsu, T., and Abe, H. (1982): Liver and serum lipid peroxide levels in patients with liver diseases, in Lipid Peroxides in Biology and Medicine, ed. by Yagi, K., Academic Press, New York, pp. 285-293.

13. Schacterle, G.R., and Pollack, R.L. (1973): A simplified method for the quantitative assay of small amounts of protein in biologic material. Anal. Biochem., 51, 654-655.

14. De Matteis, F., and Gibbs, A.H. (1975): Stimulation of the pathway of porphyrin biosynthesis in the liver of rats and mice by griseofulvin, 3,5-diethoxycarbonyl-1,4-dihydrocollidine and related drugs: Evidence for two basically different mechanisms. Biochem. J., 146, 285 287.

15. Williams, M., Van der Zee, J., and Van Steveninck, J. (1992): Toxic dark effects of protoporphyrin on the cytochrome P-450 system in rat liver microsomes. Biochem. J., 288, $155-159$

16. Van Steveninck, J., Boegheim, J.P.J., Dubbelman, T.M.A.R., and Van der Zee, J. (1988): The influence of porphyrins on iron-catalysed generation of hydroxyl radicals. Biochem. J., 250, 197-201.

17. Morehouse, K.M., and Mason, R.P. (1990): The enzymatic one-electron reduction of porphyrins to their anion free radicals. Arch. Biochem. Biophys., 283, 306-310. 